\title{
A necessidade de contextuação cultural das práticas psi: considerações preliminares
}

\author{
Sarita Brazão Vieira \\ Universidade Federal da Paraíba
}

\begin{abstract}
Resumo
O objetivo deste artigo é contribuir para a reflexão sobre a predominância, no campo da saúde mental, de um modelo explicativo no qual a ênfase é a esfera físico-orgânica do sujeito em detrimento de outras formas de abordar o processo saúde/doença. Discute-se a questão da eficácia terapêutica considerando a existência, na população trabalhadora, de formas distintas de interpretação e tratamento para lidar com o sofrimento denominado "psíquico". Na tentativa de compreender o porquê destas serem praticamente desconsideradas pelos sistemas de conhecimento e intervenção terapêutica da psiquiatria, psicanálise e psicologia é que se recorreu às investigações desenvolvidas no campo antropológico sobre a concepção moderna de pessoa.
\end{abstract}

Palavras-chave: Manifestações culturais, Eficácia terapêutica e Ideologia Individualista.
Key words: Psychical suffering,

Cultural manifestations, Therapeutic effectiveness.

\begin{abstract}
Cultural context and psychological practices: Introductory remarks. The predominance of an explicative model in the field of mental health which emphasizes the physical-organic sphere of the subject, regardless of other forms of approaching the health/disease process is discussed. The understanding of aspects regarding the therapeutic effectiveness and the different interpretations and treatments to deal with the psychical suffering is sought. The main axis of the analysis is grounded on anthropological investigations about the modern concept of person.
\end{abstract}


A idéia da presente reflexão surgiu do texto Brasil doublebind: loucura e cultura de Leibing (1996), no qual é aborda da a relação entre cultura e doenças psiquiátricas. Consideramos importante levantar alguns pontos sobre a questão de como o universo cultural pode contribuir para o entendimento do enfoque moderno no campo da saúde mental e a eficácia dos seus sistemas terapêuticos.

A partir do ponto de vista sócio-cultural, recorremos a alguns estudos, para compreender o porquê da predominância de um modelo médico-psiquiátrico no qual a ênfase é a esfera físico-orgânica do sujeito em detrimento de outras formas de abordar o problema.

Sabemos que fatores culturais e históricos juntamente com outros, biológicos e ambientais, contribuem para a produção dos comportamentos psico-sociais e que cada sociedade elabora suas próprias distinções em relação aos padrões de normalidade, desvio e anormalidade. É, portanto, da interação dialética entre história, cultura e biologia que surgem as bases para a compreensão do campo da saúde mental.

\section{Doenças psiquiátricas x Doenças mentais}

Leibing (1996) afirma que a opção pelo uso do termo "doenças psiquiátricas”, e não “doenças mentais”, serve para salientar uma visão etnopsiquiátrica que considera a psiquiatria como uma etnomedicina entre outras formas de cura. É a construção social da psiquiatria que permite certos estados humanos serem conhecidos por esquizofrenia, neurose e outros. A autora pretende compreender como certos tipos de culturas podem influenciar tanto o aparecimento de doenças psiquiátricas, quanto produzirem mecanismos que podem proteger as pessoas. No caso da realidade brasileira, é demonstrado como categorias culturais como o "jeitinho" e o "malandro", antes mecanismos que protegiam os indivíduos numa sociedade rígida e hierarquizada, voltam-se hoje, em uma estrutura confusa, contra os mesmos.

A partir daí, surgem várias questões. Não há dúvidas de que as causas das doenças psiquiátricas são múltiplas, mas é o corpo e, em geral, as alterações neuroquímicas que recebem mais a atenção dos 
pesquisadores. Compreender o porquê deste fato não é tarefa das mais simples e, nesse sentido, acreditamos que o enfoque cultural tem muito com o que contribuir. Concordamos com sua idéia de que o corpo pertence a uma pessoa, e esta faz parte de uma ou de várias culturas. $\mathrm{O}$ mundo de referência de uma pessoa se constrói ao longo da história, num processo contínuo e dinâmico nunca acabado e é, simultaneamente, universal para pessoas de um mesmo grupo e idiossincrático, pois a cultura não é algo abstrato e determinista; "se cultura interfere na nossa concepção do mundo, ela também modula a nossa experiência com o lado doente dentro de nós, num 'princípio de interdependência"' (Leibing, 1996, p. 3).

Freud (1930/1974) demonstra em O Mal-Estar da Civilização como certas estruturas de uma sociedade podem existir de modo tão conflitante contra as necessidades das pessoas que populações inteiras podem tornar-se neuróticas. Estava criada a "base científica" para um diagnóstico dos povos, que influenciou vários estudos antropológicos; Ruth Benedict, Georges Devereux, entre outros. No entanto, para não cair num tipo de pensamento etnocêntrico e considerar certos povos como inferiores, é preciso que sintomas encontrados numa dada cultura sejam interpretados no contexto em foram produzidos.

Leibing recorre a Erich Fromm para mostrar que a relação entre saúde mental e cultura depende da estrutura da sociedade em que vive um ser humano. Este autor enumera algumas necessidades básicas (Grundbedurfnisse) que precisam ser garantidas para a existência de um modo de vida saudável, tais como: as necessidades de relacionamento, de transcendência, de se sentir enraizado, possuir uma identidade e ter um sentido de orientação.

\section{A Questão da Eficácia Simbólica e As Alternativas Terapêuticas.}

Pensamos que, nos tempos atuais, em virtude do que se transformou o viver nas grandes cidades, as chances de a maioria da população que vive do trabalho conseguir a satisfação das necessidades acima mencionadas sejam mínimas. 
Como avaliarmos as repercussões deste fenômeno à partir do que é revelado pelos indicadores de saúde mental? Neste sentido, considerando o que até aqui foi exposto e, partindo do pressuposto de que a população que recorre aos serviços de atendimento psicoterapêutico possui interpretações e visões de mundo (Weltanschauung) próprias, nos indagamos sobre os mecanismos de natureza sócio-culturais que impedem que suas concepções sobre o adoecimento "psíquico" sejam praticamente desconsideradas.

A esse respeito, as idéias desenvolvidas por Ropa e Duarte (1985) sobre as causas do problema, mostram que as explicações para o fenômeno podem ser múltiplas. Alguns estudos revelaram que a inadequação do instrumental terapêutico nesta área se dá em vários níveis; sejam limitações do próprio saber psiquiátrico-psicológico, seja pela falta de agilidade das estruturas institucionais ou, mesmo, devido às contradições sócio-econômicas entre os profissionais que prestam os serviços e a população visada.

Como solução para este impasse é sugerida, por exemplo, a introdução de alterações técnicas na prática terapêutica mas, raramente, como bem eles observam, há um questionamento sobre a eficácia como um todo do próprio sistema psiquiátrico-psicológico e, menos ainda, uma preocupação em saber da existência na população de modelos alternativos para lidar com esse momentos de crise.

Por mais perpassadas que estejam pela ideologia dominante, as classes trabalhadoras guardam (mesmo que a título de resistência) manifestações culturais próprias. Essas abrangem não apenas as práticas específicas de uma medicina popular como também diversas outras terapêuticas decorrentes de visões de mundo alternativas (Duarte \& Ropa, 1985, p.181).

Tal fato levou os autores a questionar a suposta universalidade do nosso saber e duvidar do nosso esquema de interpretação e tratamento como o único existente para lidar com estes períodos de crise e sofrimento denominados como "psíquicos". No entanto, é ressaltado que não se trata de advogar uma atitude populista que tivesse a preocupação pura e simples de buscar um reencontro das classes trabalhadoras com uma cultura da qual tivessem sido alijadas mas, antes, 
de questionar a aplicação indiscriminada de um modelo psiquiátricopsicológico.

Segundo Figueira (como citado em Duarte \& Ropa, 1985), todos os recursos que uma sociedade põe à disposição de sujeitos que estão doentes ou passando por momentos críticos, podem ser chamados de terapêuticos. A respeito da existência de alternativas terapêuticas, como podemos relacionar modos tão diferenciados como a umbanda e a psicanálise? Segundo o autor, a eficácia destas práticas vai depender da possibilidade que elas têm de funcionar enquanto sistemas simbólicos. Desse modo, como sistemas simbólicos, tanto uma quanto a outra podem fornecer uma explicação para esses momentos, derivada de uma visão de mundo que lhes são próprias e propor soluções para o sujeito. $\mathrm{O}$ que era antes uma experiência desordenada e anômala passa, através da versão fornecida pelo sistema simbólico, a ser reintegrada dentro de um sistema conhecido de crenças e valores. A questão da eficácia terapêutica depende dessa possibilidade de produção de uma verdade sobre o sujeito. A esse respeito, Piera Aulagnier (como citado em Duarte \& Ropa, 1985), ao tratar das condições de "analisabilidade" da psicanálise, afirma que o engajamento psicanalítico se faz entre dois discípulos da teoria freudiana, um que seria o herdeiro do saber do texto e outro que seria herdeiro de uma cultura que deu origem a esse saber.

Como compreender a escolha de um sistema simbólico? Figueira (como citado em Duarte \& Ropa, 1985) acredita que são muitos os parâmetros que orientam tal escolha e esses, são avaliados em termos da distância que os separam ou os aproximam do sistema simbólico e dos quais o sujeito não tem consciência, pois a opção não é refletida e voluntária, uma vez que depende tanto das características sociais do sistema quanto das características do sujeito.

Duarte \& Ropa (1985) assinalam dois níveis que agem concomitantemente em termos da participação nesses sistemas; um, que seriam os sistemas institucionalizados, que se encontram nas sociedades complexas à disposição dos sujeitos para fins terapêuticos como a psicanálise e a umbanda, e um outro, que seriam os sistemas de representações, que fundam os sujeitos tornando-os passíveis de "clientelização" por alguns desses sistemas institucionalizados. Al- 
gumas das características dos sujeitos tendem a aproximá-los mais do sistema médico-científico do que de outros. Essa questão tem sido objeto de várias interpretações teóricas. Os mesmos autores apontam três características culturais que tenderiam a afastar os membros das classes trabalhadoras das práticas psicoterápicas; recorrem a Boltanski, para explicar o grau de reflexividade da cultura somática, que expressaria o quanto alguém é capaz de observar o próprio corpo e discriminar sensações para torná-las comunicáveis; uma outra característica é dada pela teoria da verbalização de Berstein, que mostra como é significativa para a análise das diferenças entre sistemas simbólicos, a necessidade de um certo "equipamento lingüístico" para, por exemplo a transmissão de experiências íntimas e, finalmente, o fenômeno da problematização no qual estariam implicadas as noções de problema e de causalidade.

Observamos nas sociedades modernas e complexas, uma grande variedade de sistemas simbólicos e uma profusão de visões de mundo que, muitas vezes, são conflitantes umas com as outras, o que torna difícil para os indivíduos se situar e escapar da desorientação. A penetração de novas ideologias ou sistemas simbólicos em determinados segmentos sociais pode provocar um "desmapeamento" dos sujeitos em relação àqueles que anteriormente orientavam suas existências.

Dessa forma, os estudos que tivessem como objetivo específico o conhecimento do conjunto de manifestações culturais de uma determinada população, estariam contribuindo para o desvelamento de uma questão mais ampla ou seja, a da difusão diferencial da visão de mundo psicologizante, intimamente comprometida com a constituição e difusão da ideologia individualista.

Duarte (1995), ao desenvolver uma investigação antropológica sobre as configurações da perturbação nervosa e os "nervos " nas classes populares, mostrou como a representação dos estados de saúde e doença dependem intimamente do estatuto cultural da noção de pessoa (ou da noção de pessoa que predomina em cada sociedade), particularmente quando se refere à questão das perturbações físico-morais. Ao comparar o código dos "nervos"- enquanto específico das perturbações - com o de outros segmentos da população, 
percebeu uma oposição de categorias, uma vez que nas classes superiores a noção predominante é a de uma realidade "psicológica".

Desse modo, para compreender a oposição entre estas categorias explicativas, foi preciso recorrer à historicidade das formas, configurações ou estatutos da perturbação físico-moral na tradição ocidental. Duarte (1995) chegou a um modelo tripartido: o humoral ou melancólico; o nervoso - que se constitui em oposicão ao anterior, a partir do século XVII - e, finalmente, o modelo psicológico. A convivência entre distintos modos de conceber a pessoa e suas perturbações é, atualmente, um dos problemas mais delicados, principalmente para os sistemas de conhecimento e intervenção terapêutica da Psiquiatria, da Psicanálise e da Psicologia. Daí, a relevância de seu estudo, pois a superação intelectual desses limites só pode ser conseguida através da percepção da historicidade dos nossos sistemas de representação da Pessoa.

Nesse sentido, consideramos o estudo desenvolvido por Venâncio (1992) como pertinente à presente investigação, uma vez que toma como referência o campo psiquiátrico para compreender a construção de pessoa moderna. Seu objetivo foi o de visualizar, especificamente, de que maneira as representações, que davam forma e conteúdo às ofertas terapêuticas, estavam construindo uma noção de pessoa individualizada, característica das sociedades modernas.

A mesma autora assinala que nas últimas duas décadas no sistema médico-psiquiátrico brasileiro, a chamada "nova Psiquiatria" reunia em seu interior uma série de discursos e práticas em interação ${ }^{1}$. Foi aí observada uma ramificação do modelo médico-psiquiátrico em um modelo que ela denominou de médico-psiquiátrico "moderno", que trouxe novos subsídios à versão clássica no que se refere a atenção da esfera físico-orgânica do paciente.

Em sua especificidade, no entanto, a versão "moderna" do modelo médico-psiquiátrico parece estabelecer uma ruptura em relação ao ponto de interseção da chamada versão "clássica" com a psicanálise. Desse modo, pode-se entender a referência à psicofarmacoterapia como a "psiquiatria do século XXI" ou uma "psiquiatria de resultados". (...) ela enfatiza a utilização criteriosa de medicamentos numa abordagem individualizada a respeito somente, da situação "presente" do paciente. (Venâncio, 1992, p. 22) 
O que é importante de se chamar a atenção é que a não-referência à historicidade "individual" coaduna-se mais com a preocupação sobre a doença propriamente dita e menos com a investigação dos fatores causais da doença.

\section{As conseqüencias da primazia do modelo "psicológico"}

A propósito da constatação da autora acima, de que a doença mental passa a ser vista independente de sua possível causa específica, está implícita a idéia de uma "predisposição" do indivíduo (provavelmente de ordem genética). Consideramos oportuno o estudo desenvolvido por Fabrega (1996) sobre as bases históricas e culturais do diagnóstico psiquiátrico. Ele mostra que as doenças estão presentes em todas as culturas e que refletiriam anormalidades de comportamento que, por sua vez, são determinadas, ou mesmo modeladas pelo conjunto de convenções de uma sociedade. Estudos pertinentes de natureza transcultural ou histórica devem ser vistos como oferecendo versões alternativas das doenças psiquiátricas. $\mathrm{O}$ mesmo autor propõe, diante da constatação da influência de fatores culturais e históricos nos sistemas de classificação e diagnósticos psiquiátricos, a viabilização de um sistema que seja "culturalmente sensível". Mesmo sabendo da complexidade da tarefa, é preciso que todas as pessoas "psiquiatricamente doentes" de uma sociedade sejam incorporadas adequadamente.

Dado que uma interação dialética envolvendo biologia, sociedade e cultura produz desordens psiquiátricas e leva ao desenvolvimento de conhecimento e aos sistemas de diagnóstico e classificação, deve ser evidente que nem a DSM-IV nem qualquer sistema de classificação em psiquiatria será totalmente completo. (Fabrega, 1996, p.10)

A meta deve ser modesta, conseguir a melhor síntese do conhecimento acumulado sobre o tópico da cultura e doenças psiquiátricas e incorporar este conhecimento ao sistema de diagnóstico.

Para concluir, gostaríamos de chamar a atenção para a existência da íntima relação entre a visão de mundo psicologizante e a ideologia 
individualista. O tema, além de bastante complexo, não é propriamente o foco da presente reflexão. No entanto, conforme já apontando por diversos autores como Michel Foucault, Louis Dumont, Luis Fernando Duarte, Jurandir Freire Costa, Sérvulo Figueira, entre outros, algumas características culturais como "interiorização psicológica", “intimização", "auto-exame" e "privatização dos sentimentos" fazem parte de um mesmo processo de difusão do individualismo e mesmo de uma estratégia disciplinar que, fundamentalmente, teve como principal alvo as camadas médias e altas da sociedade moderna.

Pensamos, por exemplo, em todo o cuidado com a higiene, difundido no início do século entre as famílias de elite no Brasil, que levou a uma maior atenção dos indivíduos para com suas particularidades físicas e morais. Esse cuidado com a saúde física acarretou um aumento da importância do psiquismo.

Sabemos que toda sociedade desenvolve mecanismos para definir um lugar para o indivíduo-agente empírico, na medida em que este tem de assumir papéis, responsabilidades e deveres conforme seu sexo, idade e posição na hierarquia social. Conforme assinalado por Velho (1994), este processo não se dá sem tensão, mas a emergência e o desenvolvimento da ideologia individualista moderna mudam a direção e o sentido da problemática, pois nem sempre o seu perfil aparece com nitidez. "Nem todo comportamento ou atitude individualista, no sentido de servir aos interesses do indivíduo, expressa uma visão de mundo em que o agente empírico é o sujeito moral e unidade mínima significativa" (p. 49).

A cultura ocidental moderna traz como marca a hegemonia de uma visão de mundo individualista, na qual o indivíduo se apresenta como sujeito autônomo e instaurador. No entanto, como mostra Russo (1996), o surgimento do indivíduo como categoria central do pensamento ocidental, traz em si uma nova dominação. Esse indivíduo que se livra das teias da tradição (à família, à linhagem e à terra), torna-se submetido a um outro tipo de poder, o do Estado. $\mathrm{O}$ "sujeito-cidadão", indivíduo autônomo, livre e igual, faz parte de uma natureza desencantada, ou seja, desligada de qualquer cosmologia religiosa e transcendente, mas que tem suas leis de funcionamento ditadas pela 
razão e, portanto, passíveis de serem compreendidas e desvendadas pela razão humana. É esta que detém as luzes capazes de iluminar o funcionamento do mundo.

É preciso que os profissionais que trabalham na área de saúde mental reflitam de forma mais apurada sobre os fundamentos que guiam suas práticas pois, de acordo com Ropa e Duarte (1985), assim como o indivíduo livre e igual da representação moderna distingue-se da pessoa socialmente qualificada presente nas visões de mundo holistas, também os saberes modernos se apresentam como livres e iguais, sob a forma de nossas ciências, recortadas contra as cosmologias totalizantes representadas pelo pensamento religioso e pelo filosófico.

A constituiçao das "ciências psicológicas" representaria, neste sentido, o apogeu da progressiva segmentação individualizante: um saber "autônomo" sobre sujeitos "autônomos" (p.193).

\section{Conclusões}

Em cada sociedade existe uma representação dos espaços de saúde e de doença que está intimamente relacionada com uma noção de pessoa. Quando se trata das estruturas de conhecimento referentes às perturbações que convencionou-se denominar "psíquicas", os estudos desenvolvidos no campo da antropologia nos revelam a importância dos sistemas de referência que segmentos da população criam para explicar estes fenômenos. Procuramos ressaltar a relevância deste conhecimento, para que os limites sociais e culturais dos modelos terapêuticos disponíveis possam ser permanentemente questionados. Como se trata de uma reflexão teórica, falta-nos o respaldo da prática, portanto consideramos este trabalho como uma contribuição preliminar ao tema.

\section{Referências}

Duarte, L. F. (1995). As três configurações da perturbação no ocidente e os nervos das classes populares. Cadernos de Psicanálise: Corpo e Representação, 12, 77-95. 
Fabrega, H., Jr. (1996). Cultural and historical foundations on psychiatric diagnosis. In J. E. Mezzich \& A. M. D. Kleinman (Orgs.), Culture and psychiatric diagnosis, A DSM-IV perspective (pp. 314). Washington: American Psychiatric Press.

Freud, S. (1930/1974). O mal-estar na civilização. In Obras completas: Vol. XXI. Rio de Janeiro: Imago.

Leibing, A. (1996). Brasil double-bind: loucura e cultura. Jornal Brasileiro de Psiquiatria, 45, 3-6.

Duarte, L. F., \& Ropa, D. (1985). Considerações teóricas sobre a questão do "atendimento psicológico" às classes trabalhadoras. In S. Figueira (Org.), Cultura da Psicanálise (pp. 178-201). São Paulo: Brasiliense.

Russo, J. (1996). O sujeito cidadão. Trabalho apresentado na Mesa Redonda "O Estado e o Cidadão" no XIV Congresso Brasileiro de Psiquiatria, Belo Horizonte (mimeo).

Velho, G. (1994). Individualismo e cultura (3a. ed.). Rio de Janeiro: Zahar.

Venâncio, A. (1992). O campo terapêutico psiquiátrico: a tensão físico-moral da noção de pessoa moderna (Relatório final de pesquisa). Rio de Janeiro, FAPERJ-PPGAS/MN/UFRJ.

\footnotetext{
Nota ${ }^{1}$ A pesquisa foi realizada no Instituto de Psiquiatria da UFRJ e concluída em 1992. Visava ampliar a análise do espaço psiquiátrico com o objetivo de compreender os métodos e as escolhas terapêuticas ali desenvolvidas. A propósito, a autora ressalta que a locução "nova psiquiatria” é expressão própria ao campo psiquiátrico (e datada, confome Birman e Costa, e Basaglia, como citados por Venâncio, 1992)
} 
306 S. B. Vieira

Sarita Brazão Vieira é profes-

Sobre o autor sora do Departamento de Psicologia da Universidade Federal da Paraíba e Doutoranda do Instituto de Psiquiatria da UFRJ. Endereço para correspondência: Universidade $\mathrm{Fe}$ deral da Paraíba/ Departamento de Psicologia/CCHLA - Cidade Universitária, João Pessoa, PB. CEP 58.000. Tel: (083)-248-1180, Email:sarita@zaz.com.br 